Revista Iberoamericana, Vol. LXXIV, Núm. 224, Julio-Septiembre 2008, 713-725

\title{
NACE UNA SINGULARIDAD: \\ EL PRIMER LIBRO DE ROSENMANN-TAUB ${ }^{1}$
}

\author{
POR \\ JAIME Concha \\ University of California, San Diego
}

A mediados del siglo pasado la poesía chilena se hallaba en un estado de consolidación y fluidez. Consolidación, porque ya a esas alturas se había grabado el perfil definitivo de los grandes poetas de la primera parte del siglo. La muerte o la obra -a veces ambas- lo habían bruñido y burilado. Es el tiempo en que se publica el Canto general, si no el más importante, sin duda el libro de mayor difusión entre los que integran el vasto corpus nerudiano. Un par de años atrás había muerto Vicente Huidobro, poniendo fin a una aventura lírica y vanguardista de órbita internacional. En lo que toca a la Mistral, la que va a ser su última colección, Lagar, se encontraba en plena elaboración. Su parábola vital se interrumpiría muy pronto, en 1957. Junto a ellos, y para señalar sólo a otros dos poetas de valor similar, Pablo de Rokha había publicado ya lo principal de su obra, que incluye Los gemidos, Escritura de Raimundo Contreras, Jesucristo y tantos libros más; por su parte, Ángel Cruchaga Santa María -afín en cierto grado al autor que es el foco de este estudio- había construido lo más aéreo de su obra desde 1915 en adelante, con centro y gravitación en la década de los veinte. Con todo, había asimismo un factor de fluidez, que derivaba en gran medida de la nueva situación creada en los años de posguerra. Muy cerca de 1949, fecha en que aparece el poemario que aquí se estudia, se editó una antología de poetas chilenos a cargo de Hugo Zambelli. En esa selección, que me parece recoge muy bien el sistema de preferencias que empezaba a imponerse en el país, se incluyó prácticamente a todos los representantes de la nueva vanguardia. Están Eduardo Anguita, que por esa época todavía resultaba asociado con las innovaciones huidobrianas; Braulio Arenas, fundador de la "Mandrágora", exponente voluntarioso de un surrealismo nativo; los notables innovadores Jorge Cáceres y Enrique Gómez-Correa; el emergente, ya entonces distintivo Mahfud Massis; y, muy especialmente, autores como Nicanor Parra y Gonzalo Rojas, que signarían marcadamente la segunda mitad poética del siglo. Ausentes están, sin embargo -y no podían dejar de estarlo puesto que resultaban novísimos-, Miguel Arteche, que apenas había empezado su producción dos años antes , publicando el mismo 1949 un poemario sobresaliente, Una nube; y el poeta y el libro que me van a ocupar a continuación, David Rosenmann-Taub, autor de Cortejo y epinicio.

\footnotetext{
1 Agradezco a Virginia Sarmiento su ayuda para precisar ciertos datos biográficos del autory comunicarme materiales que de otro modo me habrían sido inaccesibles. Su pronta respuesta a mis consultas me salvó de cometer varias inexactitudes.
} 
En medio de este panorama bien definido aunque no estático de fuerzas creadoras, el libro de Rosenmann destaca por la peculiaridad de su impronta vanguardista, íntimamente ligada a mi ver con el tipo de composición que organiza el libro y, como es natural en toda obra lírica, con su tono, sus temas y la modalidad emocional que en ella prevalece.

David Rosenmann-Taub, el autor de Cortejo y epinicio, nace en Santiago en 1927. En su primer libro habla a veces del barrio Echaurren en que pasó su infancia. Es hijo y descendiente de inmigrantes polacos. Entre los rasgos biográficos mínimos que hay que retener para una mejor comprensión de su obra, habría que considerar el cultivo familiar de las artes, sobre todo de la música. En un nivel profesional, Rosenmann estudia en el Conservatorio de Música de Santiago y practica el piano privadamente pero con asiduidad. Tengo entendido que es también compositor y, por si todo esto fuera poco, no ha dejado de cultivar el dibujo. Educado en el Instituto Pedagógico de la Universidad de Chile, se lo asocia habitualmente con el grupo de poetas del cincuenta. Con quien exhibe mayor amistad y cercanía es sin duda con Armando Uribe Arce; a él lo une igualmente cierta reverencia obsesiva por la forma poética. En lo temático y estilístico, no obstante, sus caminos discurren por separado, dando lugar a modalidades diferenciadas.

El libro inicial de Rosenmann-Taub sale a luz a fines de 1949. Ha sido reeditado recientemente, en los primeros años del presente siglo, por la editorial LOM, como parte de un sorprendente renacimiento de la poesía del autor, que ha empezado a concitar vasto interés en Europa, Norteamérica y América Latina. Entre estas fechas hay que consignar una segunda edición que tiene lugar en Buenos Aires en 1978, que modifica substancialmente el libro y que habrá de pasar casi sin cambios a la última edición chilena. 1949, 1978, y 2002 son, por lo tanto, los hitos reconocibles en la historia de este libro singular. Si se compara a las tres ediciones, es posible observar que hay diferencias apreciables en la presentación material del libro. Al formato menor, casi mínimo, del libro de 1949, sucede una edición abultada y voluminosa, la argentina, que se estabiliza, podríamos decir, en una publicación a todas luces intermedia en su cuerpo físico, la de LOM. Y es claro también que los cambios introducidos por la segunda versión, que pasarán en gran medida a la tercera, son muchos y relevantes. Sin embargo, aunque parezca contradictorio postularlo, no se trata en absoluto de otro libro, sino del mismo libro renovado, corregido y, sobre todo ... ¡reducido! Con un aprendizaje poético ya en plenitud, el autor vuelve treinta años después sobre su obra temprana y la densifica -es decir, la poda y la comprime- a veces con crueldad. Rosenmann borra, elimina versos y secuencias de versos, dando por resultado un volumen presidido por el arte de la elipsis y efectos de discontinuidad. El libro subsiste, sin embargo, porque no se modifica su esquema orgánico original: permanece el mismo número de secciones, con levísimas alteraciones de uno que otro nombre. ${ }^{2}$ En el

2 El colofón de la primera edición, más detallado que lo habitual, da la fecha final del "20 de diciembre de 1949", aclarando que "los originales fueron aceptados por Cruz del Sur en enero del año que termina". Aparte de otros datos, da cuenta de El mensajero como "segundo tomo de Cortejo y epinicio". Este dato es importante para reconstituir el proyecto original de Cortejo y epinicio como un amplio ciclo que incluía, entre otros, el libro que comento. El mensajero sólo vendrá a ser conocido en el 2003, también editado por LOM. Y aun otra observación: a la altura de su primer libro, el autor firma todavía Rosenmann Taub. Posteriormente puso un guión para 
estudio que sigue, no me interesa una comparación sistemática entre el alfa y omega de este camino creador; sólo indicaré incidentalmente las modificaciones parciales que me sean reveladoras por echar luz retrospectiva sobre la versión original. Es el nacimiento de la poesía de Rosenmann-Taub lo que me preocupa centralmente, en su índole embrionaria -con sus titubeos, détours y búsquedas preliminares. Es así como emerge la singularidad en que va a consistir y desarrollarse, por más de medio siglo, la creación de este poeta cuya voz, reconocida ya en el ámbito latinoamericano, empieza a ser escuchada y valorada con creciente atención en el mundo de habla española y más allá de él.

ENIGMAS

Cortejo y epinicio es un libro de rara complejidad. La distribución de los poemas en el conjunto, el sentido ambiguo de sus núcleos temáticos, la sintaxis siempre discontinua de las imágenes y símbolos principales, hacen de esta obra un pequeño laberinto poético cuya exploración parece indispensable como paso preliminar. La obra de Rosenmann-Taub resulta así ostensiblemente vanguardista, o casi (explicaré más adelante esta restricción). Surgido cuando la primera vanguardia ha dado ya sus frutos más plenos en la poesía chilena, instala e instaura otra -otro tipo de modalidad vanguardista- que se hará más comprensible a la luz del desarrollo ulterior de su obra en particular y de la lírica nacional en general.

La complejidad del poemario se concentra e intensifica en ciertos nudos que para el lector resultan particularmente enigmáticos. ¿A qué responde el título del libro, que no parece tener correspondencia alguna con las áreas más explícitas de su contenido? ¿Cuál es la significación concreta del "Preludio", poema inicial que encapsula con extrema tensión la parábola de todo el conjunto? ¿Por qué los núcleos emocionales más intensos tienden a coincidir con una visión arcaica, incluso folklórica o popular de la muerte, en una articulación que pudiera ser decisiva para la visión del mundo y de la vida que el libro aspira a comunicar? Estos, más algunos otros, son detalles que pueden ayudar, al ser analizados, a acceder a la mentalidad poética del Rosenmann-Taub inicial (a su imaginario, según la parla actual). Son nudos, como he dicho, haces de tensión y de contradicciones productivas en los que es posible ver, si no me equivoco, un dinamismo lírico-metafísico actuando en sus líneas esenciales.

\section{Título}

Como acabo de indicar, los términos “cortejo” y “epinicio” no encuentran correlato alguno en las áreas que el libro traza. Si “epinicio” representa un género bélico por antonomasia -himno triunfal o canto de victoria- obviamente es lo que el libro excluye deliberada y sistemáticamente. El tema guerrero, con las relativizaciones que introduzco de inmediato, brilla por su ausencia en todo este extraño "epinicio". "Cortejo”, en cambio, si bien por contigüidad al otro término pudiera adquirir el matiz de desfile militar o algo similar (ver más abajo), tiene también la connotación habitual de acompañamiento funeral que resulta

unir los apellidos de sus padres, cosa que mantiene en la actualidad. Su nombre por lo tanto, debe escribirse hoy Rosenmann-Taub. 
más cercano al clima dominante en la serie de poemas. En principio, entonces, y en su mayor parte, el rótulo del libro se revela decididamente equívoco.

El nexo más visible que es posible determinar entre rótulo y cuerpo de la obra es de orden más bien peritextual: ${ }^{3}$ es la portada del libro, que (tendríamos que presumir), o fue elegida por el autor, o por lo menos conocida y aprobada por él. Entre dos columnas barrocas con toda su parafernalia de adornos, curvas y geometrías irregulares, en cuya base es posible entrever los utensilios de la escritura (pluma, rollo manuscrito), vemos arriba una cinta ondulante con la divisa latina "Vivit post funera virtus". Más abajo, un águila o ave fénix despliega sus alas flamígeras sobre una corona que se posa en una figura semioblonga, la que encierra a un león rampante más bien a mal traer. En el medallón que sigue se contienen el título del libro y el nombre del autor. Al pie de la página es posible leer el sello editorial bajo el que se imprime el libro, Cruz del Sur. ${ }^{4}$

Como se ve, lo barroco y lo heráldico promueven y juntan allí signos de otra época, que trasmiten una sensibilidad muy distante a lo que el libro comunica en su lectura. El único detalle relevante es el "post funera" de la sentencia superior, pese a la envoltura de apotegma moral con que se lo formula, siguiendo el arte y la retórica de los emblemas característicos del siglo xVII.

Hay otro indicio, éste interno a la obra, que podría echar luz sobre el significado del título. A lo largo de todo el libro, sólo en la sección "Sarcasmo" es posible identificar un poema denominado "Oda heroica” que podría avenirse con lo que anuncia el encabezado global del poemario. El poema en efecto comienza: “Qué vida miserable, qué resplandor de hoguera”, y concluye: “Guerrera altiplanicie. ¡Qué resplandor de hogueras!” Es la única vez, si no he leído mal, que se menciona algo concordante con el sentido del título. Es un minúsculo elemento que hay que tener en cuenta por razones de una cierta contigüidad.

Efectivamente, el poema que inaugura todo el subconjunto de "Sarcasmo" se intitula "Fábula” y posee una curiosa estructura rítmica. A diferencia de los poemas restantes, está concebido en ritmo anfibráquico - esto es, en pies de tres sílabas con acentuación en la segunda. (Las otras variantes del pie trisilábico son el verso dactílico y el anapéstico). Este tipo de ritmo da al poema una andadura reconocible y una cadencia musical que inmediatamente resuena en la memoria del lector de poesía en español: "La fila de tigres reales se engarza con emperadores...”, y el último segmento se inicia: “Avance la fila de tigres reales...”. Sin mucho esfuerzo y sin forzar demasiado las cosas, uno cree escuchar en seguida el famoso y -hélas!- celebérrimo arranque de la "Marcha triunfal” dariana: "Ya viene el cortejo.../ Ya vienen los claros clarines...”.

Esta "Fábula”, entonces, casi contigua a la "Oda heroica” (y ambas, no se olvide, pertenecientes a una sección llamada "Sarcasmo”), nos remite al poema dariano y modernista por excelencia donde las glorias militares y la pompa guerrera se ven ensalzadas en versos imposibles de olvidar. Lo mismo que la Mistral, para quien el banquete modernista no

3 Neologismo feo pero útil, ya de uso corriente, introducido por Genette para referirse a la entidad material del libro: tapas, portada, solapas, lomo, sobrecubierta comercial, etc., que envuelven el texto y sus elementos paratextuales (dedicatorias, epígrafes).

4 La intervención del autor hallaría confirmación en el hecho de que casi la misma portada se mantiene -en grande- en la edición argentina. 
resultaba de ningún modo suculento ni atractivo, Rosenmann-Taub nos deja aquí una oblicua parodia de un mundo bélico reducido a bestiario. (Eso es, en el fondo, lo que significa a secas la “fábula” propiamente tal). Lo cual, de más está decirlo, tiene mucho sentido apenas concluida la segunda guerra mundial con su séquito de calamidades y atrocidades $\sin$ fin. El título, en consecuencia, se revelaría como una sarcástica expresión de las gestas destructoras de la humanidad y una versión paródica del desfile modernista. Epinicio y cortejo al revés, por lo tanto. Todo ello, sin la violencia directa y agresiva del acto vanguardista, sino de un modo oblicuo, elíptico, incluso tácito. Rasgo ya expresivo del coeficiente vanguardista y del estilo que Rosenmann-Taub empieza a cultivar.

\section{PRELUDIO}

Este breve poema que abre la colección representa un conjunto de elemento único: es sección y poema al mismo tiempo. Un carácter semejante comparten “Asfódelo”, “Impromptu”, "Homenaje a Debussy” y “De la tierra y del hombre”, aunque estos dos últimos, más extensos, muestran una mayor segmentación interior y una articulación menos lineal. Su posición y este carácter dan a "Preludio" autonomía y continuidad a la vez en la serie poemática que inaugura; es umbral y síntesis del universo de Cortejo y epinicio.

La alquimia poética no coincide necesariamente con las leyes de los procesos químicos materiales. En "Preludio" hay condensación y, también, decantación. El lenguaje poético condensa a alta temperatura palabras que, como moléculas, se ligan incandescentes, definiendo un compacto paisaje espiritual; y a través del poema, ciertos versos se decantan por su peso específico, quedando como vetas visibles y señeras en la superficie textual del poema. He aquí el poema:

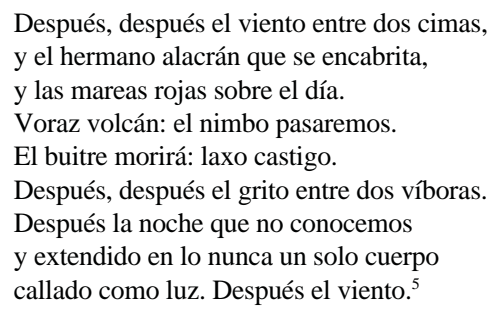

La paradoja de todo el poema puede formularse de una manera muy simple: el "preludio" remite a un horizonte póstumo, el umbral posee un colofón de muerte. El “después”, nota dominante de la pieza que se reitera como eco tantálico a lo largo de los versos, abre y cierra el poema diseñando una parábola fatal. Temporalizado según el ciclo del día ("las mareas rojas sobre el día”, "la noche que no conocemos”), el sucederse de los versos culmina en la subjetividad yacente del poeta: "y extendido en lo nunca un solo cuerpo/callado como luz”.

5 Cito siempre por la primera edición. En este caso, el poema cambia muy poco en las versiones de 1978 y de 2002. 
“En lo nunca...”, se nos dice aquí. Y en el poema siguiente se hablará de “lo lejos”. Lo nunca y lo lejos: tales resultan ser las coordenadas de un sujeto difunto que empieza a vibrar en esta poesía. En esa desgramaticalización del lenguaje habitual, el poeta crea e inventa sus propias señas para su domicilio intraterrestre. ${ }^{6}$

Por otra parte, y de un modo muy pregnante en la imaginación de Rosenmann-Taub, véase esta luz que habita silenciosa en el corazón de la noche: “en la noche...”, “callado como luz”. Son ya los términos de una dialéctica que se convertirá paulatinamente en un núcleo esencial en la visión de Rosenmann-Taub, una ley espiritual que va a regir el cosmos de su primera poesía. En el seno de la oscuridad, en la plenitud del misterio, yace-silente y luminoso- el vestigio corporal del personaje que habita esta poesía. Este último verso y medio -cima y hondonada de todo el poema- se alarga y expande como una gran cinta ondulante, comprimiéndose en un monosílabo perfecto, el átomo y el principio de la luz.

DESCRIPCIÓN

Cortejo y epinicio consta de las siguientes secciones: "Preludio”, ya vista; “Pagano”, con tres poemas; "Sphaera”, una de las secciones más extensas, con once poemas; "Continuo éxtasis”, cuatro poemas que tienden a poetizar una experiencia mística de estatuto indeciso; "Impromptu"; "Sarcasmo", mencionada más arriba, consta de cinco piezas y tiene gran afinidad temática con la posterior sección "Sadismo”; "Recreo”, con cuatro; “Asfódelo”; "Sadismo", con siete poemas; "Estampas” incluye igualmente siete composiciones; "Fortaleza" es la otra sección más extensa y comprehensiva, con doce poemas; el "Homenaje a Debussy”, aunque despliega el motivo de la cabellera de Melisenda, levemente insinuado en el texto de Maeterlinck (1892, Actos II y III), parte de un preludio del músico francés; "En la lava sensual”, con nueve unidades textuales, incluye (y concluye con) un par de “Asfódelos”; y, finalmente, "De la tierra y del hombre” cierra el libro de un modo expansivo, en gesto claramente sinfónico.

Una simple ojeada a estos subtítulos y al tipo de organización en que se inscriben muestra de inmediato que se trata de un conjunto poético variado, plural, con articulaciones internas multivalentes. Lejos de la organización posmodernista del libro, en espacios o aposentos claramente discernibles (como se puede observar, por ejemplo, en la Desolación mistraliana, 1922, o en Crepusculario, 1923, de Neruda), y distante también de la técnica vanguardista, que opera más bien por metamorfosis e irradiación desde un centro (ver El espejo de agua, 1916, y los Poemas árticos, 1918, huidobrianos), aquí se trata en cambio de zonas porosas y permeables, que interactúan complejamente entre sí, intercambiando valores y configurando una geografía poética relativamente autónoma. Más que una imagen arquitectónica, se impone la de un paisaje de horizonte abierto, con sus propios caminos y una ley de correspondencias de las que sólo el poeta parece guardar la clave.

6 Es una tendencia marcada y un signo estilístico del lenguaje del primer Rosenmann-Taub: "que es el canto más grave y la copla más sangre...” (59). El poeta saca de sus casillas -de sus casilleros lógicos-a la lengua, desplazando el sentido hacia otras categorías. Así, el adverbio deviene nombre, el sustantivo se adjetiva, etc. 
En su sentido más amplio, “Pagano” nos trasmite una visión distante y distanciada del espectáculo actual de las cosas, en la medida en que el sujeto se hunde -paganamente-en su éxtasis de muerte. El adverbio en neutro, "lo lejos”, deja de ser una parte invariable de la oración y se declina constantemente a lo largo del primer poema de la sección:

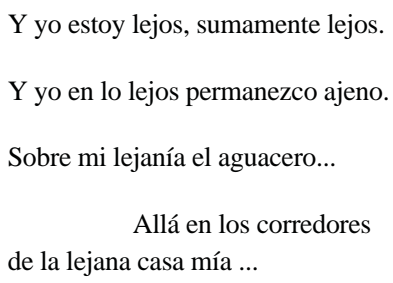

Esta separación es la distancia inconmensurable que instituye la muerte, convirtiendo lo más cercano y propio, "la lejana casa mía”, en eco funeral y en rima secreta de la muerte. La rima es interna y casi simétrica: "lejanía”/ "lejana casa mía”. Por ello, el poema finaliza coherentemente -con la coherencia emocional y estética de toda poesía- en el territorio protegido y natal de la huesa: "Y entre los cobertores/de mi huesa, rumores de otros dioses". Estos “dioses” benignos y bienhechores - en cuanto póstumos y trasmundanos- son el signo de lo "pagano" que engarza el subconjunto. Constituirán un Leitmotiv en la sección así bautizada, reapareciendo en los dos poemas siguientes (“¿Cuándo, dioses, empieza el invierno?”; “Penetré entre los dioses...”). Y entre los detalles preciosos del primer poema de este trío, hay que señalar que, en medio del predominio sutil de una eufonía asonante, la única consonancia plena se instala al final entre los “corredores” de la casa y los “cobertores" de la huesa. Los valores se trasmutan, se intercambian en el mismo plano fónico del verso, gravitando hacia el polo ideal de lo yacente que es lecho, abrigo y protección en las lejanías del mundo. Es que "la casa mía” ha devenido "mi huesa", dando la articulación esencial de todo el poemario. En la cascada de consonancias que signa el desenlace del poema I: "corredores”, “cobertores”, la rima interna de "rumores”, transitamos imperceptiblemente, sin solución de continuidad, al después temporal y subterráneo del "Preludio”: el abismo de la huesa o de la fosa que será la coda constante en no pocos poemas del libro.

\section{DiALÉCTICA DE LA NIÑEZ Y DE LA MUERTE}

"Sphaera” (o simplemente "Esfera” en las ediciones posteriores) contiene un movimiento alternante y contrastante respecto a “Pagano”. Si aquí prevalecía la distancia y la separación (la antigua apallagé platónica del Fedón), en la tercera sección del libro se impone un ánimo semejante al impar libro de Prado, El llamado del mundo (1913): auscultación atenta y conmovida de las voces y los ecos de las cosas. La separación no es, por tanto, absoluta ni definitiva. Como Lázaro en esa obra de Prado, el sujeto difunto de Rosenmann-Taub quiere levantarse de su entierro para volver a habitar el mundo que dejó. Pero también aquí es posible observar la peculiaridad y los rasgos diferenciales de esta temprana poesía que ya se vincula y empieza a dialogar con algunos de sus destacados precedentes. 
"Pagano” era aún poesía algo complaciente; en "Esfera” empezamos a escuchar el sonido percutiente de una voz más intensa, que pronto llegará a ser la del poeta que hoy conocemos. El primer poema arranca con sorprendente brío: "Con su cuerda invisible me ahorca/la baldía intemperie; los duendes/zarandéanme a gajos agónicos”. Imágenes hoscas, de singular extrañeza, que traen a veces a la memoria recuerdos más precisos: "Estropajo que tengo de emblema/se me enrosca en el cuello".

En su sintaxis, en su torsión retórica, en su hiriente plástica corporal, estos versos no dejan de traer a la mente el estilo mistraliano de Tala y, quizás, adelantos de Lagar. Es una deuda que el poeta reconocerá explícitamente poco después y que será importante para evaluar el tipo de vanguardia que empieza a practicar.

Desde este primer poema la sección se coloca bajo el signo de un Dios único. En esta situación vivida como “destierro” (¡en la plenitud de la tierra, paradójicamente!), el poeta siente el anhelo del mundo (“Aun me anhela una gota de agua”, “... y mi sino está tenso”) para terminar implorando "Dios mío”, mientras en el poema siguiente, de verso más breve, la imploración es ya deprecación mayor: "levantamos las manos/para que Dios les hable”.

La concentración de "Esfera" en el tema de la muerte puede comprobarse fácilmente a través del encabezamiento de algunos de sus poemas: "Diálogo sepulcral”, "Elegía y Kadisch", aludiendo este último término a una plegaria de duelo que se reza en la sinagoga. "Moi vivant" es un detalle humorístico, sangrientamente irónico, porque alude a un sujeto finado que recorre los siglos rescatando jirones del pasado histórico. Y con ello llegamos a uno de los poemas magistrales de este libro, que destaca absolutamente no sólo en el conjunto, sino que es pieza única de la poesía chilena. Me refiero a "Canción de cuna”, que ocupa un puesto central, el sexto, en una serie de once poemas y que, muy aptamente, lleva el subtítulo esclarecedor de "Funerales”. La contradicción entre vida y muerte es meridiana y se subraya una vez más: en su honda esencia, la canción de cuna no es otra cosa que su antítesis misma, funerales.

El poema retoma un aire de balada o de Lied que ya había comenzado a aparecer un poco antes y que habrá de intensificarse más tarde. Estribillos fuertemente musicales dan un vuelo melódico y melodioso que contrasta con el tema lúgubre, casi macabro, de lo que allí se poetiza. Hay, probablemente, influencia emocional remota de los Kindertotenlieder de Mahler, ciclo de cinco poemas basados en poemas de Friedrich Rueckert (1901-4); incluso esta "Canción de cuna” llega a veces a imponérsenos con la fuerza del gran poema inicial en el itinerario de Celan, su “Tango...”, o "Fuga de muerte”, la “Todesfugue” de mayo de 1947. Veamos con cierto detalle el poema de Rosenmann-Taub.

Mediante el género familiar de la canción de cuna y con la voz de una "nana” tan misteriosa como las madres mistralianas de Ternura (1924), Rosenmann-Taub elabora un doloroso poema cuyos nudos emocionales son diminutivos sabiamente distribuidos ("con trapitos de musgo...”, “y a tus manitas”, “mi lucerito”, “corazoncito”, “afán chiquito”, “y abrigaré el potito”...) y el contexto violento, material y macabro de la muerte: “con gusanos bonitos”, “con babero de barro”, “con pañales de hormigas...”. La síntesis terrible la van a dar las formas de interpelación al niño muerto: “niño podrido”, “niño violáceo”, que llevan el sello de la gran definición de la muerte que dará Rosenmann-Taub en el poema contiguo, "La que hiede”, exacerbación sin duda de una tradición mistraliana que el mismo poeta recoge a través de pseudocitas o referencias ambiguamente intertextuales (ver “La lentísima”, 40-1). 
Esta “Canción de cuna/Funerales” constituye así el otro polo en la estructura bitemática de toda la sección. En esta "esfera” hay un giro que acerca y reunifica al muerto con el mundo y con la vida, y hay también un proceso que hace ingresar a los niños en el seno oscuro de la muerte. Estos dos aspectos justifican que la sección concluya de un modo entre apodíctico e irónico -a medias verdadero, a medias desengañado- con una fórmula que no deja de ser memorable: "Porque si nos morimos,/que nuestro Paraíso sea volvernos niños".

Se lo ve: la muerte infantiliza, por obra y gracia del macabro morir de los niños. Esta dialéctica circular, que el poeta desarrolla en tonos muy diversos a lo largo del libro y a veces de su poesía posterior, es parte decisiva de una visión metafísica cuyos acentos religiosos son perceptibles, aunque sean difíciles de calibrar. Lo que me es claro en este punto es que el poeta echa mano a una fusión increíblemente eficaz de una tradición folklórica y popular que se da en el país, pero que él combina y hace remontar a linajes y ancestros espirituales que vienen de mucho más lejos. Lo atávico y lo arcaico se fusionan potentemente en este tipo de poesías (baladas, canciones); y es fácil advertir que ambas ramas, estilos o planos de su creación se imbrican en el mismo respeto y admiración que el poeta siente por la obra de la Mistral y, sobre todo, por cierta zona de su poesía, la de Ternura y partes de Tala en especial.

Si se mira a vuelo de pájaro la totalidad de "Sphaera” y se pone atención a sus grandes líneas de sentido, sobresale un contraste dramático, casi un choque, entre el clímax de la muerte que casi todo lo domina, y un apaciguamiento "pagano" que pone el acento en el ciclo y su fertilidad. Después de los funerales de "Canción de cuna”, "Diálogo sepulcral” y "Elegía y Kadisch", siguen y cierran la sección el minúsculo poemita "Genetrix”, e "Immortalis”. El primero dice concisamente: “Acabo de morir: para la tierra/soy un recién nacido”. El otro concluye con el paraíso póstumo infantil mencionado más arriba.

"Sphaera"es, entonces, el ciclo en sentido propio, la conciencia del retorno inagotable de la fertilidad contra el fondo de la peripecia dramática-individual, humana-de la destrucción.? En esta conexión, el poema "Impromptu" se revela bien como ocupando un puesto cardinal en el decurso de estos motivos temáticos. Como he dicho, es un poema relativamente aislado, que cubre por sí solo una sección entera con el mismo nombre. Sin que sea posible justificar el género musical al que se adscribe, es claro que su función principal es retomar y sintetizar lo desarrollado hasta ese momento, y preparar el vuelco en los poemas que siguen. El inicio parece centrarse en las operaciones mismas de la disolución:

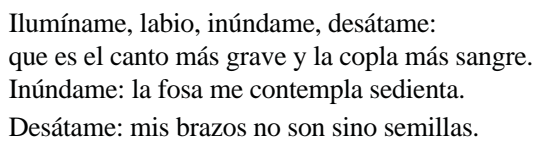

El léxico de tipo vegetal y agrario, aquí bien acusado, retoma los motivos y el contorno de la experiencia "pagana” de incorporación a la tierra, con sus signos suplementarios

\footnotetext{
7 En las ediciones posteriores el poeta invierte el orden de estos poemas, situando en penúltimo lugar al que cerraba la sección. "Immortalis" pierde su nombre y queda simplemente como "XVI". Más que todo, el poema cambia mucho. Unos versos que eran capitales para la red de sentido de toda la sección en 1949 prácticamente desaparecen: “Un niño es un anciano que mañana será/a escondidas de Dios, una criatura/de pan de sortilegio” (47).
} 
de fertilidad y crecimiento. Es la donación personal vista en términos de rito y sacrificio. Pero a la vez los signos crísticos y de un Dios único se van a perfilar a través de imágenes inconfundibles (“clavetean mi alma”) y mediante la imagen sintética del "árbol de lepra” que viene poco después y que resume poderosamente todos los cauces poéticos desplegados hasta ese momento: el paradigma vegetal pagano (reelaborado en otra sección a la luz del mito clásico de "Dafne”), el signo cristiano del madero y el motivo bíblico veterotestamentario de Job. Metamorfosis pagana a la manera de Dafne, estaurocentrismo evangélico (madero y crucifixión tematizados en el amplio poema "Gólgota”), salmo y teodicea de la antigua Tora: tres componentes y dimensiones con los que el libro de Rosenmann-Taub retrabaja sutilmente una gama y una red de paradigmas de la poesía chilena (Prado, Mistral, Cruchaga Santa María), unificándolos creadoramente en su primer libro y confiriéndoles un cuño sobremanera singular.

El poema se pliega estupendamente retomando en su coda final los motivos iniciales y abriendo nuevas sendas de iluminación:

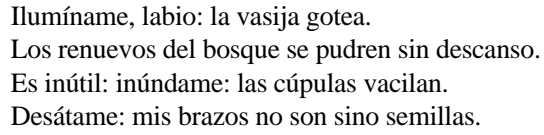

El poema siembra así, en su desembocadura, todo el claroscuro fundamental de esta metafísica de la tierra y de la donación. La putrefacción vegetal es semilla, contrastando fuertemente con el “niño podrido” de la canción funeral, donde la parca que preside la infancia sólo representa la ley y la amenaza de disolución.

Por su posición de relativo aislamiento, vale la pena poner en relación "Impromptu" con su congénere "Asfódelo", situado algunas secciones más adelante. De tema muy diverso y casi opuesto, el último poema es principalmente una visión urbana que, con horror expresionista, revela lo feo y lo sucio de la noche citadina, tema caro y ampliamente tratado por el movimiento de vanguardia internacional desde Trakl, por lo menos. A pesar de este ambiente y contexto, el poema finaliza: “Soy en mi sueño un denso escupo negro,/silencioso, en la orina pegajosa,/y brillando en la sombra como un astro”.

En esta especie de recuperación final del sujeto -transfiguración desde el fondo del horror nocturno- hallamos la poetización complementaria y adversa de la experiencia "pagana” que daba inicio al poemario: adversa, porque no es de raíz rural sino que se enfoca en el siniestro lado urbano de la experiencia social; complementaria, porque este "astro" sobreviviente en medio de lo abyecto es un avatar de esa "luz" enterrada que observábamos en la obertura del libro. Viaje al fondo de lo macabro humano, la poesía organiza su propia fórmula de autosalvación. ¿Magro “epinicio” después del “cortejo”?

OTROS ASPECTOS

Sibien lo ya descrito me parece contiene las principales líneas de la visión de RosenmannTaub, la gran variedad de su primer libro desarrolla zonas de experiencia que no es posible reducir a un orden único. Pese a todo, creo que hay un cauce de fondo que da unidad a los 
afluentes en los que se ramifica y distribuye el poemario. Para dar una idea no demasiado esquemática de su contenido, mencionaré algunos tópicos que emergen con mayor nitidez en las secciones posteriores del libro.

"Fortaleza” representa la sección más directamente ligada al ámbito autobiográfico, con razón dedicada "a mi hermana Eva”. Lo que más resalta es justamente la experiencia de la cotidianidad familiar con sus ritos, situaciones y ambiente infantil. Recuerdos y objetos de la infancia reinan por doquier. También aparece el barrio de la niñez. "Retrospectiva" abre coherentemente la sección, imponiendo un ángulo de poetización que es el del farewell adolescente al tiempo de la infancia. Esta se desvanece para siempre, quedando sólo ecos: el estribillo en dísticos pareados de "Retrospectiva" o la rima fantasmal de "fragancia” que se sugiere en el hermoso poema "LV”, “Como un golpe de luz...”:

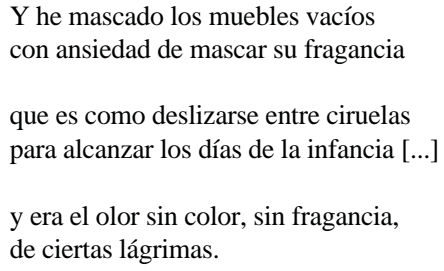

Por el arte puro y simple de la rima; mediante el juego casi freudiano de asonancia y consonancias; por una red sutil de rimas internas, el poeta trasmite vívidamente lo muerto y lo supérstite del niño y de su infancia. Otros poemas, como "Solera”, elevan a la infancia hasta un plano de extrañeza y de misterio.

Si “Fortaleza” representa la despedida adolescente de la infancia, "En la lava sensual”, como su título bien indica, se trata de la iniciación juvenil en lo sexual y en lo erótico. Lo que empieza siendo un minúsculo "Madrigal”, se exacerba e hiperboliza pronto en "Eternidades”; y en el antepenúltimo poema, "LXIV”, el autor subraya y sintetiza el sentido que atribuye a la relación erótica:

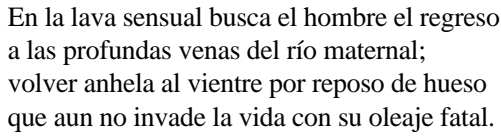

Los versos fluyen notablemente modulados, forjando una vez más -ahora en la esfera y en el terreno del eros- el paisaje de la vida y de la muerte. El "río maternal" se abre y desemboca en el "oleaje fatal”. Como en el gran poema dariano de 1905, "Lo fatal”, en que el título condensaba lo "mortal” y lo "natal” al mismo tiempo, también aquí las rimas comunican todo el choque de la antítesis. Entre ellas, en medio de ellas, queda el "hueso" casi como la versión masculina de la huesa y de la fosa mencionadas insistentemente a lo largo del libro.

Por último, ya para concluir esta somera descripción, "De la tierra y del hombre” instaura un ceñido diálogo entre el sujeto y la tierra, que se revela así como el elemento y 
la figura dominantes en la esfera total de Cortejo y epinicio. En gran medida, este poema -que se llamará “Pasión” en las ediciones posteriores- intensifica una serie de rasgos y procedimientos formales que el poeta había utilizado en la serie precedente. Los ecos, dobletes y rimas pareadas dan paso aquí a una isócrona, casi monótona, reiteración de la tierra como eje central del poema y de la visión de Rosenmann-Taub:

La tierra lame los cuerpos y los cuerpos caen a la tierra.

Agua de tierra y sal de tierra penetran a los huesos.

Incluso en su disposición gráfica estos versos imitan una simetría quiral -en quiasmo, dirían los retóricos- que hace presente la constante y avasallante dominación de la tierra. En ella, los "huesos" abren y cierran el poema, clausurando en realidad el compacto universo de toda la colección: "Y el dormido no sabe/si lo que su sueño roza/es la tierra o sus huesos".

Así concluye, definitivamente, este libro admirable, el primero de un nuevo poeta que lleva hoy, a la altura del 2006, alrededor de sesenta años de intensa y persistente actividad poética, con una decena o algo así, de obras publicadas. Merece, sin duda, una mayor y más sostenida atención.

De este modo, Cortejoy epinicio nos propone en esencia el enlace misterioso-doloroso y gozoso a la vez- de la muerte y la niñez; no de la muerte por un lado y de la niñez por otro, porque eso sería simplemente una banalidad o un par de banalidades. El enlace es el movimiento y la conjunción de ambas, el de la muerte en la niñez y la repristinación constante de lo muerto. Tal vez sea éste uno de los sentidos posibles del enigmático título, su dialéctica más entrañable.

Por otra parte, y según se ha podido ver, Cortejo y epinicio se vincula con una tradición de vanguardia endógena, que tiene egregios precedentes en la obra de Prado, Mistral y Cruchaga, por citar sólo los casos más claros y afines al poeta. En su aspecto más externo, la tradición se refleja bien en la actitud del autor frente a la versificación y a la cuestión métrica en general.

Esta vanguardia endógena, que no rompe sino que enriquece y potencia el arte métrico posmodernista, resulta ser también una vanguardia divergente entre las muchas líneas vanguardistas que surgen en el país a mediados de siglo. Debido a los componentes étnicos, religiosos y culturales que son parte de la circunstancia humana del poeta, Cortejo y epinicio constituye, en el arranque de la obra de Rosenmann-Taub, una rama desprendida y libérrima, no asimilable al árbol central de este movimiento poético. Tal es su puesto peculiar, tal vez su mayor singularidad. 


\section{BIBLIOGRAFÍA}

Darío, Rubén. Cantos de vida y esperanza [1905]. Barcelona: Bolsillo, 2004.

Maeterlinck, Maurice. Pelléas et Mélisande [1892]. Bruxelles: Labor, 2001.

Prado, Pedro. El llamado del mundo; Flores de cardo, Karez-I-Roshan, y textos inéditos. Prólogo, edición y notas de René de Costa. Santiago: Editorial Universitaria, 1971. Rosenmann-Taub, David. Cortejo y epinicio. Santiago: Cruz del Sur, 1949. Cortejo y epinicio. Buenos Aires: Esteoeste, 1978.

Cortejo y epinicio. Prólogo de María Nieves Alonso. Santiago: LOM, 2002. El mensajero: cortejo y epinicio II. Santiago: LOM, 2003.

Zambelli, Hugo. 13 poetas chilenos (1938-1948). Valparaíso: Imprenta Roma, 1948. 